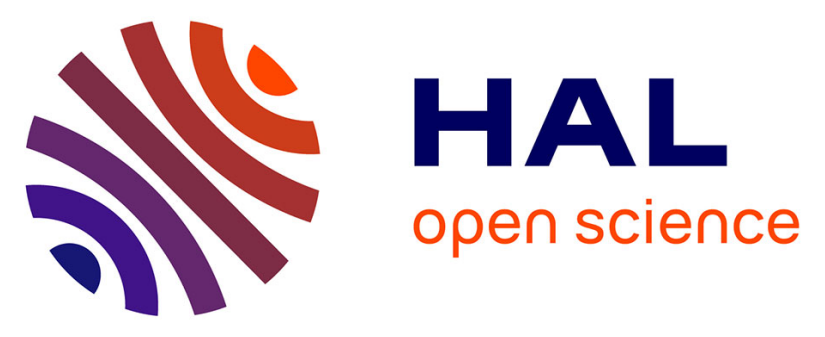

\title{
An unusual evolutionary strategy: the origins, genetic repertoire, and implications of doubly uniparental inheritance of mitochondrial DNA in bivalves
}

Donald Stewart, Sophie Breton, Emily E Chase, Brent M Robicheau, Stefano

Bettinazzi, Eric Pante, Noor Youssef, Manuel A Garrido-Ramos

\section{To cite this version:}

Donald Stewart, Sophie Breton, Emily E Chase, Brent M Robicheau, Stefano Bettinazzi, et al.. An unusual evolutionary strategy: the origins, genetic repertoire, and implications of doubly uniparental inheritance of mitochondrial DNA in bivalves. Pontarotti P. Proceedings of the 24th Evolutionary Biology Meeting at Marseilles, Springer, Cham, pp.301-323, 2020, Evolutionary Biology-A Transdisciplinary Approach, 10.1007/978-3-030-57246-4_12 . hal-02927307

\section{HAL Id: hal-02927307 \\ https://hal.science/hal-02927307}

Submitted on 1 Sep 2020

HAL is a multi-disciplinary open access archive for the deposit and dissemination of scientific research documents, whether they are published or not. The documents may come from teaching and research institutions in France or abroad, or from public or private research centers.
L'archive ouverte pluridisciplinaire HAL, est destinée au dépôt et à la diffusion de documents scientifiques de niveau recherche, publiés ou non, émanant des établissements d'enseignement et de recherche français ou étrangers, des laboratoires publics ou privés. 
An unusual evolutionary strategy: the origins, genetic repertoire, and implications of doubly uniparental inheritance of mitochondrial DNA in bivalves

\author{
Donald T. Stewart, Sophie Breton, Emily E. Chase, Brent M. Robicheau, Stefano \\ Bettinazzi, Eric Pante, Noor Youssef, and Manuel A. Garrido-Ramos
}

\begin{abstract}
Mitochondrial DNA (mtDNA) is typically passed on to progeny only by the female parent. The phenomenon of "doubly uniparental inheritance" (DUI) of mtDNA in many bivalve species is a fascinating exception to the paradigm of strict maternal inheritance of mtDNA. In this review, we survey the current state of knowledge of DUI, and discuss several active areas of research in this field. Topics/questions covered include: the number of times DUI evolved (once or multiple origins), the link between DUI and sex determination, the role(s) of mtDNA-encoded non-oxidative phosphorylation genes (i.e., ORFan/orf genes) in freshwater mussels, the function of conserved sequence motifs and sperm transmission elements in mtDNA of marine mussels, the challenges of annotating mtDNA genomes of DUI species, the presence of unorthodox features in venerid mtDNA, whether or not orf DNA sequences are useful in species-level identification of freshwater mussel, and finally, whether or not there are obvious benefits of DUI. For each topic we also highlight important avenues for future research within this fascinating field of mitochondrial evolutionary biology.
\end{abstract}

\title{
Contact information
}

D. T. Stewart (corresponding author) 
Department of Biology, Acadia University, Wolfville, NS, B4P 2R6, Canada

e-mail: don.stewart@acadiau.ca

S. Breton

Département de Sciences Biologiques, Université de Montréal, Montréal, QC, H3C 3J7, Canada e-mail: s.breton@umontreal.ca

E. E. Chase

Institut Méditerranéen d'Océanologie, Aix-Marseille University, 13288 Marseille, France

e-mail: emily.chase@mio.osupytheas.fr

B. M. Robicheau

Department of Biology, Dalhousie University, Halifax, NS, B3H 4R2, Canada

e-mail: brentrobicheau@acadiau.ca

S. Bettinazzi

Département de Sciences Biologiques, Université de Montréal, Montréal, QC, H3C 3J7, Canada

e-mail: stefano.bettinazzi@umontreal.ca

E. Pante

Littoral, Environnement et Sociétés Joint Research Unit, 7266 Centre national de la recherche scientifique, Université de La Rochelle, La Rochelle, France

e-mail: eric.pante@univ-lr.fr

N. Youssef

Department of Biology, Dalhousie University, Halifax, NS, B3H 4R2, Canada

e-mail: n.youssef@dal.ca

M. A. Garrido-Ramos

Departamento de Genética, Facultad de Ciencias, Universidad de Granada, 18071, Spain 
e-mail:mgarrido@ugr.es

\section{An Overview of Doubly Uniparental Inheritance of Mitochondrial DNA in Bivalves}

Doubly Uniparental Inheritance (or DUI) of mitochondrial DNA is a highly atypical system of mitochondrial DNA inheritance observed in various bivalves (Breton et al. 2007). Since its discovery (early 1990s; e.g. Fisher and Skibinski 1990; Hoeh et al. 1991; Zouros et al. 1992) the field of DUI research has steadily grown. As summarized in a series of review articles, species that possess DUI typically exhibit the following features (but exceptions have been noted in the literature; e.g., Ghiselli et al. 2013; Passamonti and Plazzi 2020): (1) two sex-associated mtDNA lineages [a sperm-transmitted male lineage and an egg-transmitted female-transmitted lineage], (2) females are typically homoplasmic, whereas males are heteroplasmic, (3) male somatic tissue is dominated by female-transmitted [F-type] mtDNA, whereas male gonad, and specifically spermatozoa, contain exclusively male-transmitted [M-type] mtDNA, (4) a relatively fast rate of molecular evolution for both types, but especially M-types, (5) in some lineages of bivalves, the M- and F-types occasionally recombine, giving rise to an F-type mtDNA molecule that is mostly composed of F-type protein/RNA coding genes, with the insertion of a copy of the control region from the M-type, and (6) the presence of open reading frames with no immediately obvious homology to typical mitochondrial genes associated with the electron transport chain or ATP synthesis (Breton et al. 2007; Passamonti and Ghiselli 2009; Breton et al. 2011; Zouros 2013; Zouros and Rodakis 2019).

At present >1200 papers have been published on DUI (based on Google Scholar search for "doubly uniparental inheritance" articles from 1990 onwards). Popular areas of research since 
the phenomenon was first described in Blue mussels of the genus Mytilus, have included: the taxonomic distribution of DUI, the rate and pattern of molecular evolution of the F- and M-type genomes, gene complement and genetic features of both $\mathrm{F} \& \mathrm{M}$ genomes in various bivalve orders and families, patterns of tissue specific and intracellular gene expression of the $\mathrm{M} \& \mathrm{~F}$ genomes, the role of recombination of $\mathrm{mt}$ genomes on efficiency rates of electron transport chain complexes and even sperm swimming speed, as well as many other fundamental biological properties. Nonetheless, many features of this unique molecular phenomenon remain unknown. Indeed, because DUI differs so fundamentally from the rule of strict maternal inheritance found in all other animals, Zouros (2020), and Zouros and Rodakis (2019) have recently argued that this phenomenon deserves greater attention from the broader cell biology, molecular biology, and genetics communities.

Herein, we review the current state of knowledge in several areas of DUI research and identify what we consider to be the primary areas of future investigations. We focus on the following themes in this review: origin(s) of DUI (did it evolve once or multiple times?), DUI and sex determination, open reading frame (orf) genes in freshwater mussel mitochondrial genomes (their role in sex determination/sexual development), conserved DNA sequence motifs and sperm transmission elements in the mitochondrial genome of Mytilids, issues in annotating DUI genomes, unorthodox features in venerid mitochondrial genomes, using $f$-orf sequences to improve species-level identification of freshwater mussel species, and finally, we investigate the potential benefits of DUI (in particular, to organismal fitness).

\section{The Origins of Doubly Uniparental Inheritance of Mitochondrial DNA in Bivalves: Did it Evolve Once or Multiple Times?}


To our knowledge, doubly uniparental inheritance (DUI) of mitochondrial DNA is only found within the bivalved mollusks, but not all lineages of bivalves exhibit DUI. A recent paper found that DUI has been documented in over 100 species from 12 families of bivalves (Gusman et al. 2016). The number has grown in the past four years (e.g., Pante et al. 2017), and will undoubtedly continue to grow as more of the $>9000$ known bivalve species are studied (Huber 2010). The lineages of bivalves that exhibit DUI that have been studied most extensively include the marine mussels of the order Mytilida, the marine clams of the order Venerida, and the freshwater mussels of the order Unionida. Some species in the order Nuculanida also exhibit the phenomenon, but recent phylogenetic analyses suggest that these taxa are part of the Mytilida, and not part of the basal bivalve lineage, the Protobranchia (e.g., Gusman et al. 2016).

There are two primary, but not mutually exclusive, hypotheses that have been proposed to explain the origin (or origins) of DUI. The first is that having a separate male-transmitted lineage (that is constrained to be transmitted only through sperm and thus reduce the opportunity for cytoplasmic warfare sensu Hurst and Hoekstra, 1994) could allow selection to act on the Mtype mtDNA genome in ways that benefit male-associated functions (e.g., sperm swimming speed)(Breton et al. 2007; Jha et al. 2008), while simultaneously avoiding the potentially deleterious effects of having two distinct cytoplasmically-transmitted genomes within a species (e.g., Hurst and Hoekstra 1994). The second hypothesis suggests that DUI resulted from a selfish genetic element that (1) invaded a sperm mitochondrial genome and (2) that managed to survive and become transmitted via sperm thereafter (e.g., endogenization of a selfish viral element in sperm mitochondria; Milani et al. 2014). Indeed, the beneficial effects of having a separate male- 
transmitted lineage could have been the focus of natural selection following the chance invasion of a selfish genetic element.

The phenomenon of DUI is demonstrably old in some lineages but more difficult to age in others. For example, Hoeh et al. (2002) demonstrated that the M- and F-lineages in freshwater mussels (Unionidae) diverged over 200 MYA (Hoeh, Stewart, Guttman 2002). Alternatively, Stewart et al. (2009) argued that because of occasional recombination of M- and F-genomes and role-reversal of a primarily F-type genome via the M-lineage in certain lineages (such as the marine mussels, family Mytilidae), the true age of DUI in these taxa cannot easily be ascertained. Role-reversal essentially resets the divergence time of the M- and F-type genomes (for all parts of the genome except for the relatively small M-type control region) to 0 . There appear to be short DNA sequence motifs in the M-type control regions that play a role in maintaining (and preventing destruction) of these genomes during development such that they safely end up in the developing male gonad and in the spermatozoa (see Kyriakou et al. 2015; Robicheau et al. 2017). Role-reversals have been directly observed in Mytilus, and therefore have been inferred in other genera in the family such as Modiolus (Robicheau et al. 2017) and Geukensia (Lubośny et al. 2020). Because these genera diverged from one another possibly as much as 400 MYA (Lee et al. 2019), the phenomenon is likely extremely old in the bivalves. Furthermore, because role reversals have been observed in another major order exhibiting the phenomenon, the Venerida (Plazzi et al. 2016), we maintain that the most parsimonious explanation regarding the origin of DUI is that it evolved once early on in the history of the bivalves (e.g., in an ancestor to the Autolamellibranchiata), but that recombination and role-reversal events have obscured the true age of DUI as originally suggested by Hoeh et al. (1997). 
DUI is, however, absent from some other major lineages of bivalves, such as the Pectinida and Ostrida. Because several hermaphroditic lineages of the family Unionidae have lost DUI (they do not retain a sperm-transmitted M-type; Breton et al. 2011), and because some species of scallops and oysters in these families exhibit hermaphroditism and extreme sexual plasticity (Collin 2013), we argue that if a Pteriomorph ancestor to the Pectinida and Ostrida passed through a hermaphroditic stage, all descendants of that particular ancestor would not possess DUI, even if some lineages re-evolved gonochorism.

In terms of future research directions in this area, we (as well as others) are exploring the role of sperm transmission elements (STEs; as will be discussed in more detail below) coded for by the M-type genomes that have been shown to interact with proteins from the male gonad but not the female gonad as first described by Kyriakou et al. (2015). We are using in silico approaches to search for evidence of these STEs in all mtDNA genomes of DUI positive species, which would provide further evidence that DUI evolved once, but is a dynamic system across the diverse lineages of bivalves.

\section{What is the link between DUI and Sex Determination in Bivalves?}

Breton et al. (2011) established a theoretical link between DUI and sex determination or the maintenance of gonochorism (i.e. separate female and male sexes). This was based on the observation that in gonochoric freshwater mussel species the F- and M-type mt genome lineages are present in females and males, respectively (i.e. these species exhibit DUI), whereas obligate hermaphroditic species lose their M-type mtDNA (Breton et al. 2011). In addition, an open reading frame (orf gene) specific to the F-type lineage (hence the f-orf) undergoes marked 
divergence in hermaphroditic taxa relative to their gonochoristic relatives. (These $f$-orf genes, the divergent $h$-orf genes found in hermaphrodites, and the distinct $m$-orf genes found in M-type genomes are discussed below in Section 3). Accordingly, DUI may be the first sex determination mechanism or sexual development system in animals that involves the mt genome (Breton et al. 2011).

Ghiselli et al. (2012) explored the hypothesized link between DUI and sex determination by comparing transcriptomic data of female and male gonads of Ruditapes philippinarum (Family Veneridae). They identified over 1500 genes with sex-biased or sex-specific expression. Of male-biased or male-specific genes, several were associated with ubiquitination. Based on known examples of the role of ubiquitin in inheritance of mitochondria, specifically in signalling destruction of paternal mitochondria (Sato and Sato 2013), and sex determination in Drosophilia (Bayrer et al. 2005) and C. elegans (Hodgkin 1987; Hansen and Pilgrim 1999; Starostina et al. 2007; Kulkarni and Smith 2008), Ghiselli et al. (2012) proposed ubiquitin as a promising candidate for a role in DUI, and consequently a connection with sex determination.

Following up on the work of Ghiselli et al. (2012), Milani et al. (2013b) analyzed the structure and location mRNA transcripts for three genes, psa, birc, and anubll in the Manila clam R. philippinarum, which, like Mytilus, has sex-biased ratios among progeny. They speculated that these genes, which are homologous to genes involved in ubiquitination in other taxa, play roles in sex determination and could help maintain (or degrade) sperm-derived mitochondria during embryonic development in males (or females, respectively) of DUI species. To pursue the potential link between sex determination mechanisms in bivalves and DUI, Capt et al. (2018) hypothesized that if ubiquitin is responsible for the maintenance or loss of M-type mtDNA in bivalve embryos, then there should be signatures of a homologous ubiquitination 
process in all species exhibiting DUI. To address this hypothesis, Capt and colleagues produced gonad transcriptomes of the DUI-positive species Venustaconcha ellipsiformis and Utterbackia peninsularis (Family Unionidae) to compare with previously published transcriptomes from $R$. philippinarum (Ghiselli et al. 2012) and Hyriopsis schlegelii (Family Unionidae; Shi et al. 2015). This work permitted the comparison of genes across distantly related species of bivalves possessing DUI. The work of Capt et al. (2018) showed that females possessed 18 differentially expressed ubiquitination genes, and 53 that were male-biased. This included two male-biased ubiquitination genes, which were absent from the female-biased group, psa6, a potential factor in sex determination and/or the sexual maturation of DUI species, and anubL1, a potential factor in the tagging of sperm mitochondria to distinguish from female mitochondria. They also included birc5 and birc2, other potential tags that could protect the male mitochondria from degradation. Capt et al. (2018) concluded that a similar set of genes related to sex determination and DUI exists among distantly related species possessing DUI.

Looking forward, Capt et al. (2018) suggested that epigenetic modifications are another interesting area for studying sex determination in bivalves, based on work by Lui et al. (2015). Transcriptomic data in Capt et al. (2019) showed a male-biased expression of DNA methyltransferases (including a DNA methyltransferase associated with mitochondrial, DNMT1), histone deacetylases, and histone acetyltransferases, all of which are related to epigenetic modifications. The exploration of the role epigenetic modifications and sex determination in DUI positive bivalves will progress with further transcriptomic analyses to document genes with male or female-biased expression. 


\section{What do we know about the orf genes in freshwater mussel mitochondrial genomes and their role in sex determination/sexual development?}

The unique mitochondrial $f$ - and $m$-orf genes and their link with the maintenance of gonochorism were discovered in freshwater mussel (FWM) species because of the presence of obligate hermaphrodites within the Unionida (Breton et al. 2011). Note that occasional hermaphrodites do occur in dominantly gonochoristic species (also true for marine mussels), and among species typically considered obligate hermaphrodites (Ghiselin 1969). Consequently, some hermaphrodites are relatively more recently diverged from their gonochoric ancestors, while some are evolutionarily quite older. For example, the paper pondshell, Utterbackia imbecillis, appears to be a relatively recently evolved hermaphroditic species (Riccardi et al. 2019). In theory, obligately hermaphroditic FWM species arise from previously gonochoristic species that have, by some means, produced hermaphrodites (Ghiselin 1969). The main hypothesis is that ancestral gonochoristic individuals/populations could be under selective pressures that favour self-fertilization, particularly if individuals are patchily distributed (Bauer 1987). Habitat modification and introduction of invasive species are two factors that have been identified as contributing to the global decline in freshwater mussels (Lopes-Lima et al. 2014), and these conditions could lead to an increase in hermaphroditic populations in the future.

Hermaphroditism has evolved independently multiple times among the families Unionidae and Margaritiferidae (Breton et al., 2011). In each of the hermaphroditic lineages, two patterns are readily apparent: (1) the M-type genome is always lost and (2) the remaining genome, which is now referred to as a hermaphroditic genome, experiences highly divergent evolution in its orf gene. The $f$-orf of the F-type genome of a gonochoric species acquires many 
nucleotide changes, and thus becomes an h-orf within an H-type genome. All h-orf genes examined to date have been extremely divergent (Breton et al., 2011; Chase et al. 2018) exhibiting highly modified hydrophobicity plots of their predicted proteins relative to the predicted proteins of $f$-orf proteins from their closely related sister taxa (Breton et al. 2011; Chase et al. 2018; Stewart et al. submitted). These modifications include additional transmembrane helices (TMHs), repeated segments of DNA, and typically an increase in overall length of the $\operatorname{orf}$ (Breton et al. 2011). However, some species' mt genomes possess $h$-orfs that do not adhere to these particular patterns (or even lack an h-orf gene), namely Toxolasma parvum, Anodonta cygnea, and Anodontities trapesialis (Chase et al. 2018; Soroka and Burzyński 2017; Guerra et al. 2017). The localisation of the f-orf protein to locations outside the mitochondria was further documented by Breton et al. (2011), in which immunoelectron microscopy techniques showed the $f$-orf protein in association with the nucleus as well as the mitochondria. It is crucial to explore expression localization not only for more $f$-orfs, but also $h$-orfs and $m$-orfs. Of most interest would be exploring these orfs along the spectrum from female gonochoristic individuals to obligate hermaphrodites. Recent work (Stewart et al. unpublished) has begun this process by using PCR primers to sequence orfs in a large number of individuals from a single species (in this case, Pyganodon cataracta) from many populations in an attempt to identify populations that may contain nascent hermaphrodites. A focus of future work in this area will be to identify recently-formed (or indeed emerging) populations of hermaphroditic freshwater mussels to collect additional data on the patterns noted above. Research questions of particular importance include: (i) whether nascent populations of hermaphroditic mussels lose their Mtypes immediately, and (ii) the degree of changes occurring over time within the $f$-orflh-orf regions. Examination of recently hermaphroditized populations/individuals versus older 
hermaphrodites should provide valuable insight into the functional capacity of $h$-orfs, and the overall role of orf regions in DUI and sexual development/sex determination.

We must also point out that exciting work is being conducted on a link between a novel category of RNA molecules called small mitochondrial highly-transcribed RNAs or “smithRNAs" by Marco Passamonti’s group in Bologna, Italy. Passamonti and colleagues suggest that these molecules may interact with nuclear gene expression to play a role in sex determination/sexual development. Although currently largely theoretical, this group has proposed that in vivo and in vitro experimentation is now warranted to assess the functionality of smithRNAs in DUI species. For details, see Pozzi et al. (2017).

\section{What role do conserved sequence motifs and sperm transmission elements play in DUI in mytilid mussels?}

A central tenant of DUI is that the heteroplasmy observed in bivalves is sex-linked (Ghiselli et al. 2019). However, for such a pattern to occur, it logically must follow that genetic mechanism(s) exist to facilitate the cellular recognition of male versus female mitochondria/mitotypes (see Plazzi and Passamonti [2019], and particularly Zouros [2020], for more advanced discussions on genetic signatures/models of DUI). Recent work on the description of sperm transmission elements (STEs) and DUI-associated orf genes has attempted to identify major regions presumed to convey female or male genetic signature(s). Studies of orf genes have gained considerable interest in the past decade (as discussed in Section 3), while the work on STEs is relatively more recent. Burzyński et al. (2003) and Zbawicka et al. (2003) early on indicated that genetic signatures associated with DUI signalling were likely housed in the 
non-coding portion of mtDNA in species exhibiting DUI, as this was the mtDNA region mainly associated with recombination events that lead to the masculinization (i.e., RM-type formation) of otherwise F-type mitochondrial genomes in Mytilids. A region later confirmed as the mtDNA Control Regions (CR; Cao et al. 2004).

In recent years, Kyriakou et al. (2015) sought to identify paternal mitochondrial signatures associated with DUI through the detailed mapping of a recombined masculinized CR mtDNA. Their analyses showed that a particular portion of the variable domain 1 region or 'VD1' of the mitochondrial CR housed a unique portion of sequence conferring a paternal signature within an RM Mytilus galloprovincialis under investigation (Kyriadou et al. 2015). Using an Electrophoretic Mobility Shift Assay technique, these authors found that the RMassociated mtDNA segment (which they termed the sperm transmission element or 'STE'): forms a protein complex associated with male gonad protein extract (also perinuclear mitochondrial associated), has a unique $\sim 22 \mathrm{bp}$ nucleotide motif, and contains presumed nucleotide folding (Kyriakou et al. 2015). In addition, Kyriakou et al. (2016) showed that the homologous mitochondrial F-derived STE sequence was not able to form a stable protein structure comparable to the M-derived STE. Collectively, this work strongly supports a role for STEs in the cellular identification of Mytilus M-types as being 'paternally derived' (Kyriakou et al. 2015,2016).

The discovery of a STE has significantly improved our understanding of DUI genetics (particularly of M-type mtDNA) and a subsequent step for STE research has been to locate STE mtDNA signatures in taxa outside Mytilis spp. In Kyriakou et al. (2015) a STE motif is specifically identified in M. galloprovincialis and M. trossulus, while Robicheau et al. (2018) extended this search by probing in silico with the 22bp STE motif in both a native and a 
degenerate (purine or pyrimidine) form. Robicheau et al. (2018) found M. edulis, M.

californianus, M. modiolus, and M. senhousia to also be harboring putative STE signatures that are relatively less conserved versus the known Mytilus-type STE signature in Kyriakou et al. (2015). These exercises have demonstrated that the 'unique' and recognizable region of the Mytilus RM-type STE (a mere 22bp) is inherently difficult to search for in lineages phylogenetically distant from Mytilus (e.g. Robicheau et al. 2018). We hypothesize two reasons for this. The first is that the motif as it appears in Mytilus may not entirely be suitable for searching in silico within other bivalve species. As an illustration, the level of sequence conservation inferred from Kyriakou et al. (2015) is $86 \%$ for an RM- versus M-type of the same Mytilus species. As one searches for this motif in taxa that are more and more distantly related to Mytilus, one would hypothesize that this low level of conservation (within males of the same species) would only continue to decrease even further, thus making it potentially difficult to locate STEs in silico even in the closest of species. The second reason is that perhaps conventional local alignment methods (namely BLAST; Altschul et al. 1990,1997) may be too stringent to identify small regions of STE similarity. The longest consecutive string of conserved nucleotides in the $86 \%$ conserved motif stated above is $7 \mathrm{bp}$ (Kyriakou et al. 2015). The least stringent BLAST parameter ‘blastn' (for shorter sequences) has a default word size seed of $11 \mathrm{bp}$ to initiate an alignment (note that the word size can be decreased further, but doing so would require foresight) (see McGinnis and Madden 2004). Accordingly, for the novice (even when picking the lowest BLAST stringency parameter with default settings), there is a rather low probability of finding a significant intraspecific STE BLAST hit using the 22 bp motif. A combination of both scenarios (extreme sequence divergence(s) and a rather small nucleotide in silico probe) may also be probable. Given these challenges, more creative means of searching for 
STEs in silico may be needed moving forward. Future efforts should continue to sequence novel bivalve M mtDNAs in the aim that additional STEs (or regions uniquely M-derived; either highly conserved or degenerate) may be found.

\section{What issues are there in annotating the mtDNA genomes of DUI species?}

Metazoan mitochondrial genomes are substantially conserved in terms of genome size, organization and gene content (Boore 1999; Gissi et al. 2008; Breton et al. 2010). Most mitogenomes fall within the $14-16 \mathrm{~kb}$ length range, have a stable gene content of 37 intronless genes and have short intergenic regions (Boore 1999; Gissi et al. 2008). The standard gene content includes a pair of genes coding for $12 S$ and $16 S$ rRNAs, 22 tRNAs, and a set of 13 genes encoding some of the protein subunits of the mitochondrial respiratory chain complexes and ATP synthase: NADH:ubiquinone oxidoreductase (Complex I; ND1-ND6 and ND4L), ubiquinone:cytochrome c oxidoreductase (Complex III; CYTB), cytochrome c oxidase (Complex IV; COX1-COX3), and ATP synthase (Complex V; ATP6 and ATP8) (Anderson et al. 1981; Garesse and Vallejo, 2001; Breton et al. 2010). Additional protein subunits of the mitochondrial machinery, as well as proteins required for mtDNA replication and expression, are encoded by nuclear genes (Boore 1999; Garesse and Vallejo, 2001). Notwithstanding, there are welldocumented exceptions to this general view, particularly in invertebrates, including larger genomes than the standard compact mitogenome, genes containing introns and gene gain/losses (Gissi et al. 2008; Breton et al. 2014). In addition, tRNA genes are extremely prone to rearrangement and recruitment (Breton et al. 2014; Plazzi et al. 2016). Particularly, mitochondrial genomes of bivalves are extremely diverse in size (the largest genome is actually that of Dreissena polymorpha, the zebra mussel, with $\sim 67 \mathrm{~kb}$; McCartney et al. 2019) and gene 
arrangement (different mitochondrial gene orderings are unique to different lineages) (Boore et al. 2004; Vallès and Boore 2006; Plazzi et al. 2013, 2016; Guerra et al. 2017). Furthermore, mitogenomes of bivalves, especially those of species with DUI, are characterized by an unusually high rate of evolution, specific non-standard gene content and long intergenic sequences of different sizes collectively called unassigned regions (URs).

Both genes and intergenic sequences of mitogenomes of species with DUI show high rates of sequence evolution. In bivalve mollusks in general, this rate is high and there is a correlation between rearrangement rates and evolutionary rates (Plazzi et al. 2016). Specifically, the atp6, atp8, nad2, nad $4 L$ and nad6 protein-coding genes were among the most divergent genes in bivalves (Plazzi et al. 2016). High evolutionary rates not only apply at the interspecific but also at the intraspecific level. F and M mtDNAs represent two highly differentiated genomes in species with DUI, a distinctive feature of both their separate evolution during millions of years and the faster evolution of the $\mathrm{M}$ genome which experience a more relaxed selective constraint than the F genome (Zouros 2013). Thus, extreme F/M mtDNA sequence divergence levels have been found in Modiolus modiolus (37-40\%; Robicheau et al. 2017b), in Geukensia demissa (31\%, but reaching $>50 \%$ in the most divergent regions; Lubośny et al. 2020), in Musculista senhousia (upwards of 32\%; Passamonti et al. 2011) and in freshwater mussels (as much as 52\%; Doucet-Beaupré et al. 2010) as well as in the marine clams Ruditapes philippinarum (34\%; Mizi et al. 2005), Scrobicularia plana and Limecola balthica ( 53\% between the $\mathrm{M}$ and $\mathrm{F}$ types for both species; Capt et al. 2020). All of these comparisons exceed the already highly sequence divergence values that were very early on identified in M. galloprovincialis, M. edulis, and M. trossulus (10-20\%; Mizi et al. 2005; Breton et al. 2006). Thus, with each bivalve mtDNA 
genome published, we often learn significantly more about the potential F/M/H sequence divergence thresholds that are possible within and between bivalve species/mitotypes.

The existence of highly divergent sequences might be the cause for difficulties annotating the "missing" atp 8 gene, a rapidly evolving gene in marine mussels, and in bivalves in general (Śmietanka et al. 2010). Bivalves and some species of Nematoda and Platyhelminthes were considered to be lacking atp8 (Hoffman et al. 1992; Breton et al. 2010). High rates of sequence divergence lead to the inference that atp 8 was absent in these species, but in fact it was demonstrated that it is present in most bivalves analyzed, even in some nematodes (Breton et al. 2010; Plazzi et al. 2016) and that the predicted atp 8 is fully functional in Mytilus edulis (Lubosny et al. 2018).

On the contrary to gene losses, DUI species are also characterized by gene acquisitions. For example, the often duplicated $t R N A M e t$ gene in Mytilidae species (Hoffmann et al 1992; Mizi et al, 2005; Passamonti et al. 2011; Śmietanka et al. 2018) among other cases of tRNA gene duplications in specific lineages (see for examples Guerra et al. 2017 and Lubośny et al. 2020). More remarkable is the duplicated cox2 gene in the F mitogenome of the clam Ruditapes philippinarum or in the M genome of the mytilid Musculista senhousia, although their roles are still unknown (Passamonti et al., 2011; Ghiselli et al. 2013; Breton et al. 2014). Mcox2e evolved from the extension of the cox2 gene in the M genome of the freshwater bivalves with DUI (Chakrabarti et al. 2006, 2007; Chapman et al. 2008). A similar extension of the cox2 gene has also been identified recently in the mytilid Geukensia demissa (Lubośny et al. 2020). The Mcox2e gene of freshwater bivalves encode a new protein equipped with multiple transmembrane helices that is localized to both inner and outer mitochondrial membranes and might function in male reproduction as a specific label determining the fate of sperm 
mitochondria in fertilized eggs (Cao et al. 2004a; Cogswell et al. 2006; Chakrabarti et al. 2007). The exciting aspect of gene gains in the mitogenomes of species with DUI resides exactly in the generation of new gene products with functions beyond metabolic roles. Thus, there exist in freshwater mussels an absolute correlation between DUI and the presence of the sex-specific $m$ orf and $f$-orf genes in the $\mathrm{M}$ and $\mathrm{F}$ mtDNA, respectively, which in turn would be directly involved in the maintenance of gonochorism (see preceding sections) (Breton et al. 2009a; 2011a, 2011b; Mitchell et al. 2016; Guerra et al. 2017). There is also a specific $f$-orf in marine mussels that has a homolog gene in the F mitogenome of Musculista senhousia (Breton et al. 2011) and codes for a functional protein, although its role in DUI or any other biological process remains to be established (Ouimet et al. 2020). The marine clam Ruditapes philippinarum also have sex-specific orfs that are expressed in the M and F mtDNA (Ghiselli et al. 2013; Milani et al. 2013, 2014). In fact, the RPHM21 protein coded by the $m$-orf of the male-transmitted mtDNA of $R$. philippinarum might be involved in spermatogenesis, reproduction and embryo development (Milani et al. 2014). All these orfs were collectively called ORFans (this name was suggested earlier to emphasize that they were additional orfs to the standard set of mitochondrial genes but with unknown function). ORFans are among the fastest evolving genes in mitogenomes and many times it is difficult to align their sequences when they belong to different species (Mitchell et al. 2016; Plazzi et al. 2016; Guerra et al. 2017, 2019). Therefore, there is still a debate about the origin of these ORFans. While the debate of their origin moves between the endogenization of viral genes (Milani et al. 2013, 2014) and the duplication of existing gene or the de novo generation from DNA sequences from the unassigned regions (URs), it has been proposed that the mORF of freshwater mussels evolved from a duplicated and diverged atp 8 
gene (Mitchell et al. 2016; Guerra et al. 2017), one of the faster evolving mitochondrial genes (Breton et al. 2010; Śmietanka et al. 2010; Lubosny et al. 2020).

ORFans are located in the intergenic sequences of the mitogenomes of species with DUI. These intergenic sequences are generically called Unassigned Regions (URs). These URs are extremely variable in number, location, and size, both among species and within species (F/M genomes), but usually possess specific and important features such as tandem repeats and dyad symmetries and, especially the largest ones, might hold the mtDNA control region (Cao et al. 2004b, 2009; Guerra et al. 2014, 2017; Robicheau et al. 2017a). For example, marine bivalves are characterized by control regions that differ between $\mathrm{F}$ and $\mathrm{M}$ genomes by having the $\mathrm{M}$ genomes small motifs called sperm transmission elements (STE) (Kyriakou et al. 2015; Robicheau et al. 2017a). For further discussion of these unorthodox features of the mitochondrial genomes, see sections 3,4 and 6 .

\section{Particularly interesting cases of unorthodox features in mt genomes of venerid bivalves with DUI.}

All presently identified freshwater mussel species with DUI possess a 3'-coding extension in their male mitochondrial cox2 gene (Mcox2) that is absent from other animals' mtDNAs (Curole and Kocher 2002; Chapman et al. 2008; Doucet-Beaupré et al. 2010; Guerra et al. 2017). This extension is translated and localized in both inner and outer mitochondrial membranes in sperm (Chakrabarti et al. 2006, 2007), and it has been hypothesized that it could play a role in the DUI system (Chapman et al. 2008). 
Recently, DUI was discovered in two new species: Scrobicularia plana (Venerida: Semelidae) and Limecola balthica (Venerida: Tellinidae) (Gusman et al. 2016; Pante et al. 2017). Their complete mtDNAs have been published, revealing an intriguing difference of $\sim 10 \mathrm{~kb}$ between the F and $\mathrm{M}$ mt genomes in both species (Capt et al. 2020). A large part of this difference is due to the exceptionally large size of the Mcox2 gene, which possesses a $>4.5 \mathrm{~kb}$ and $>3.5 \mathrm{~kb}$ insertion in S. plana and L. balthica, respectively. This insertion is absent in the Fcox2 gene of both species. In S. plana, this in-frame insertion, if translated, means that the Mcox2 gene would be 5,679bp-long and, to our knowledge, would therefore encode for the longest COX2 protein in the animal kingdom (i.e., 1,893 amino acids) (Capt et al. 2020). Although it remains to be determined whether it is indeed transcribed and translated in S. plana, it is worth noting that a similar in-frame but shorter insertion of $300 \mathrm{nt}$ has been reported in the DUI species Meretrix lamarckii (Venerida: Veneridae) (Bettinazzi et al. 2016).

Quite differently, the Mcox2 gene in L. balthica is split in two by the insertion, which divides the gene into Mcox2a, encoding the two transmembrane helices and the "heme-patch" region followed by a complete stop codon (TAA), and Mcox2b, encoding an enlarged intermembrane space and the Cua centers (Capt et al. 2020). This situation is confirmed by transcriptomic data (Pante et al. unpublished), which indicate that both regions are transcribed (i.e. with discrete, non-overlapping Mcox2a and Mcox $2 b$ transcripts). As for the insertion in $S$. plana, it remains to be determined whether Mcox2a and Mcox $2 b$ are translated in L. balthica. That said, a similar case has been described in another bivalve species, i.e. the freshwater mussel Anodonta cygnea, in which a translocation of a portion of the nad5 gene has been hypothesized to be transcribed and translated separately from the rest of the gene, with both portions possibly being assembled into a functional NAD5 heterodimer (Chase et al. 2018). 
Altogether, the observations about Mcox2 in S. plana and L. balthica raise several questions: (1) Is this gigantic cox2 gene in the male genome (or Mcox2) an artifact of the sequenced individuals or a conserved trait in each species? (2) Is this extension expressed or is it rather an intron-like sequence that is spliced? (3) If this sequence is conserved and expressed, how does it evolve relative to the rest of the gene and relative to other typical genes, and is it involved in the mito-nuclear network of epistatic interactions leading to OXPHOS functioning? Does it have a function aside from bioenergetics? At the moment, several ongoing research projects attempt to answer these questions but preliminary results obtained from additional $S$. plana male individuals indicate that this insertion is conserved among different individuals from different populations (Tassé et al. unpublished), suggesting that it is most probably functional. It is possible that these remarkable exceptions from the general mitochondrial pattern in bivalves, such as the extra $f$-orf and $m$-orf genes and the unusual features observed in the Mcox2 gene, could have adaptive explanations such as the occupation of different environmental niches and/or be related to different breeding systems such as gonochorism or hermaphroditism, or to other intrinsic genetic factors. However, it is not yet understood how and why the mitochondria of bivalves have evolved such different strategies of organizing and transmitting their mt genes. The great stability of gene content, arrangement, structure and inheritance, for more than 550 million years in many metazoan groups, suggests strong stabilizing selection for an optimal animal mt genome. The few animal groups that diverge from this pattern, such as bivalves, are thus of particular utility for investigating the potential causes of this near-universal mt genetic system stability. 


\section{Can $f$-orf sequences be used to improve species-level identification of freshwater mussel species?}

The accurate identification of mussels is not only interesting for evolutionary and taxonomic studies but is also necessary for conservation efforts of species at risk or endangered (Zieritz et al. 2010). This is especially relevant for critically imperilled animals such as freshwater mussels (Régnier et al. 2009). Freshwater mussels' vulnerability is commonly linked with anthropogenic factors, including a variety of extrinsic factors such as the loss and change of habitats, pollution, non-native species, and climate change, alongside intrinsic factors of which includes accurate species identification (Ferreira-Rodríquez et al. 2019). As Lopes-Lima et al. (2018) highlighted, there are gaps in our conservation assessments of freshwater mussels globally and these are required for effective conservation actions. Ultimately, the intrinsic factor of accurate species identification is the foundation of filling these gaps and leading to protection and rehabilitation of species at risk.

Several studies have demonstrated the intraspecific morphological plasticity of freshwater mussels due to environmental factors (e.g. Jeratthitikul et al. 2019; Inoue et al. 2013; Reis and Araujo 2013; Zieritz et al. 2010), and this is a likely factor in species misidentification. Shea et al. (2011) found an average rate of $27 \%$ misidentification of Unionidae species in their study and concluded that these rates would significantly impact mussel surveys. Given that conservation actions rely heavily on mussel surveys, we can conclude that misidentification of freshwater mussels could have a downstream effect of eventual misappropriation of conservation actions. An obvious component to solving these issues is the use of DNA barcoding (i.e. molecular markers) for species identification in mussels, which can be used alongside 
morphological identification for improving the accuracy of mussel surveys. However, recent mussel survey protocols do not include a molecular component (e.g. Smith 2006; Zieritz et al. 2014; a literature review of Freshwater Mussel Survey and Relocation Guidelines Final Report August 2016; West Virginia Mussel Survey Protocols March 2018; Freshwater Mussel Surveys: I-26 Widening Final Report August 2018).

Molecular barcoding provides a more objective way to identify and distinguish between freshwater mussel species (Hebert and Gregory 2005). Species identification by molecular markers often relies on coxl (Hebert et al. 2003), 16S rRNA, and occasionally nadl mitochondrial genes. A recent study (Robicheau et al. 2018) assessed mitochondrial protein coding genes of two recently divergence freshwater mussel taxa and suggested that the femaletype ORFan, the $f$-orf, was a useful additional molecular marker for both population and species level studies of freshwater mussels. A species level informative marker will evolve enough to detect the differences between two species while being maintained enough to detect individuals within the same species (Robicheau et al. 2018). The addition of $f$-orf sequencing data was shown to improve phylogenetic trees previously based of coxl alone in closely related freshwater mussel species. However, here the goal is not solely to improve our phylogenetic hypotheses (which are useful for testing our markers), but instead to improve the data that conservation efforts of freshwater mussels rely on. It is possible that the use of two molecular markers for preliminary work on populations, and/or in combination with large mussel surveys for verification of species identification could reduce errors in population and species reports, and subsequently correctly identify prime targets of conservation actions. Alternatively, the $f$-orf sequence could broadly be used as a primary barcode of life for freshwater mussel species specifically, although much more testing would be required. Thereby, increasing the effectivity 
of survey efforts. Ideally, whole mitochondrial genomes would be sequenced, and all individuals would be identified based on these sequences, however, careful planning and identification using both morphological and two molecular markers may help in reducing the significant misidentification of freshwater mussel species in general while maintaining relatively low-cost surveying.

\section{The potential benefits of DUI}

From an evolutionary perspective, two major fitness issues rise from having a specific genome within mitochondria: (i) the need to preserve the genetic information carried by the mtDNA from OXPHOS mutagenic by-products, and (ii) the need to maintain compatibility between mtDNAand nDNA-encoded subunits of respiratory complexes. Interestingly, the solution to these problems might reside in the very existence of anisogamy (i.e. gamete dimorphism), together with mitochondrial bioenergetics and transmission mechanism. Under the "division of labour" hypothesis, sperm would sacrifice their own genetic integrity by exploiting the OXPHOS to sustain motility, while oocytes would limit their aerobic metabolism in order to preserve their genetic integrity in quiescent mitochondria (Allen 1996). Then, the strict maternal inheritance of mitochondria in metazoans would retain the solely oocyte-derived mitochondria to be passed on to the next generations, altogether promoting genetic integrity and the avoidance of genetic conflicts through homoplasmy (i.e., a condition in which all mtDNA copies are almost identical). Although beneficial, the selective elimination of sperm mitochondria excludes males from taking part in the evolution of the mitochondrial genome. As a result, deleterious mutations for males can accumulate in the mitochondrial genome and spread in a population just by being neutral or 
beneficial in females. This sex-specific selective sieve in the evolution of the mitochondrial genome is known as the "mother's curse" (Gemmell et al. 2004).

Unlike in most animals, male and female mitochondria in DUI species contribute together to the genetic pool of progeny. The preservation (and transmission) of a sperm specific M-type mtDNA challenges the "classic" dynamics of mtDNA evolution, refuting both the "division of labour" and "mother's curse" concepts. On the one hand, it induces the evolutionary challenge to preserve the genetic integrity of both sex-specific templates to be passed on to the next generation. On the other hand, the very existence of the DUI system represents an unprecedented opportunity for the mitochondrial genome to evolve adaptively for male functions, breaking the female-driven constraints in its evolution. The strict sex-specific mtDNA segregation in DUI germline cause different selective pressures to act on the two mtDNA F \& M variants, leading them to evolve distinctly for female and male functions. Sexually antagonist selection is also supported by the extreme divergence between the F- and the M-mtDNA, ranging from $8-50 \%$ of nucleotide divergence, depending on the gene and species involved (Breton et al. 2007; Passamonti and Ghiselli 2009; Zouros 2013; Capt et al. 2020). Given the exclusive presence of the M-type mtDNA in DUI sperm, and that mutations in the mtDNA are likely to affect the functioning of mitochondrial respiration, a rational indication is that the evolution of DUI male mitochondria could embrace bioenergetic adaptations for male-associated functions, fostering sperm performance and reproductive success (Burt and Trivers 2006; Breton et al. 2007; Breton et al. 2009b).

During the last decade, several studies have investigated the potential benefits of carrying male-derived mitochondria for bivalve sperm performance (Everett et al. 2004; Jha et al. 2008; Stewart et al. 2012; Bettinazzi et al. 2020). Everett et al. (2004) and Jha et al. (2008) tested this 
assumption in the DUI species $M$. edulis, comparing motility traits between "standard" sperm, carrying the M-type mtDNA, and "masculinized" sperm, carrying primarily F-type mtDNA with a segment of M-type control region sequence (called RM-types). Interestingly, bearing the Mtype mitochondria did not provide any visible advantage in term of speed, with "masculinized" F-type sperm swimming equal or even faster than M-type sperm (Everett et al. 2004; Jha et al. 2008). Congruent results were recently found by Bettinazzi et al. (2020), who extended this investigation to various bivalves with a different mode of mitochondria transmission (i.e. SMI, whose sperm carry the maternal mitochondria, and DUI, whose sperm bear the paternal mitochondria). In sharp contrast with sperm carrying maternally inherited mitochondria (SMI system), M-type sperm of the DUI species M. edulis and $R$. philippinarum exhibit a convergent readapted phenotype, characterized by lower speed and accentuate curvilinear trajectory (Bettinazzi et al. 2020). Differences in sperm performance also reflect change in the energetic strategy that fuels sperm motility. For bivalve sperm bearing maternally derived mitochondria (SMI) both aerobic and anaerobic mechanisms of ATP production concur to sustain motility. Conversely, sperm of the DUI species M. edulis and R. philippinarum appear to strictly rely on OXPHOS in absence of oocytes, but partially switch towards a more combined strategy, implying also fermentation, once detecting egg-derived chemical cues (Bettinazzi et al. 2020). Although a concomitant change in sperm performance is controversial in these very species (Stewart et al. 2012; Bettinazzi et al. 2020), evidence exists that sperm of M. galloprovincialis do begin to swim faster and straighter towards eggs that are most genetically similar at the level of the mtDNA, but least similar at the nuclear level (Oliver and Evans 2014; Lymbery et al. 2017). Interestingly, this mechanism could potentially foster heterozygosity and cytonuclear compatibility in offspring, two conditions of likely upmost importance for heteroplasmic DUI 
species. Overall, evidences support the intriguing hypothesis that the DUI system might indeed be beneficial for sperm performance and fertilization success, at least in the species tested so far. Selection for male functions appears to promote sperm swimming in a slower, more curvilinear and strictly aerobic fashion, in absence of eggs, with the ability to undergo change in performance and bioenergetics once detecting genetically compatible eggs. These traits potentially represent an advantage for the fertilization strategy of broadcast spawning invertebrates, and the DUI system appears to exploit them, potentially enhancing endurance, survival and area covered by sperm. This would in turn maximize the chances of encountering compatible eggs, altogether promoting fertilization success and potential mitonuclear compatibility in open and turbulent marine environments (Levitan 2000; Liu et al. 2011; Fitzpatrick et al. 2012).

The evolutionary consequence of carrying two divergent mitotypes is also evident at the level of cellular and mitochondrial metabolism. First, in opposite trend to SMI species, DUI sperm exhibit a general downregulation of cellular bioenergetics when compared to oocytes. This is evident in the efficiency of key enzymes of glycolysis, fermentation, tricarboxylic acid cycle, fatty acid metabolism and even OXPHOS (Bettinazzi et al. unpublished results). At the level of mitochondrial functionality, recent findings revealed difference in the functional properties of mitochondria bearing either the paternally- or the maternally-associated mtDNA. For the SMI species tested, female transmitted mitochondria exhibit a conserved OXPHOS organization in both gametes and somatic tissues. Conversely, for the DUI species Arctica islandica and M. edulis, they express convergent OXPHOS remodelling in sperm mitochondria. M-type mitochondria in sperm and male somatic heteroplasmic tissues show functional divergence in OXPHOS activity and organization compared to F-type mitochondria present in 
eggs and female somatic tissues, involving a strong limitation of the electron transport system (ETS) by the phosphorylation system and a minimal spare capacity at cytochrome $c$ oxidase (Bettinazzi et al. 2019). Congruently, a lower activity of cytochrome $c$ oxidase (CCO) was also detected for M. edulis M-type sperm, in comparison with the F-type "masculinized" ones (Breton et al. 2009b). The existence of a specific DUI mitochondrial remodelling, together with the fact that DUI sperm energetic strategy tightly relies on mitochondrial respiration, support the expectation that the selective forces driving the evolution of sperm mitochondria in absence of SMI might affect mt encoded components of respiratory complexes, thus foster change in the OXPHOS mechanisms and organization (Breton et al. 2007; Breton et al. 2009b). The overdescribed architecture provides unusual respiratory control at the terminus of the respiratory chain, high sensitivity to oxygen content in the medium, a potential high ROS flux and, interestingly, the capacity to preserve high membrane potential in sperm mitochondria (Bettinazzi et al. 2019). Accumulating evidence supports this idea that DUI male mitochondria possess the ability to preserve a high mitochondrial membrane potential $(\Delta \psi \mathrm{m})$. This comes from the direct observation of DUI gametes $\Delta \psi \mathrm{m}$ (Milani and Ghiselli 2015) and from bioenergetic properties of sperm mitochondria in line with the maintenance of a high electrochemical gradient (Bettinazzi et al. 2019; Bettinazzi et al. 2020). As the $\Delta \psi \mathrm{m}$ depicts healthy mitochondria, it has been proposed that the ability to maintain it might play a key role in DUI paternal mitochondria preservation and transmission (Milani 2015).

The findings described here provide evidence of a robust link between the mitochondrial genotype and phenotype in DUI species. Specifically, direct selection on DUI paternally-derived mitochondria potentially appears to produce: (i) a widespread downregulation of cellular bioenergetics, detected at the level of all main energy producing pathways; (ii) the expression of 
a male-specific mitochondrial phenotype in sperm and partly in heteroplasmic soma, an OXPHOS remodelling providing unusual respiratory control at the terminus of the respiratory chain; (iii) the exhibition of a specific sperm phenotype, characterized by different performance and energetic strategy adopted, which could enhance fertilization success and mitonuclear compatibility; and (iv) the potential ability to preserve a high mitochondrial membrane potential. Overall, these findings suggest that the adaptive value of sex-specific mtDNA variants in DUI could altogether embrace paternal mitochondria preservation, male-specific energetic adaptation and fertilization success.

\section{Acknowledgements}

DTS and SB were funded by NSERC Discovery grants. EEC was funded by the European Union's Horizon 2020 research and innovation programme under the Marie Skłodowska-Curie grant agreement No713750, carried out with the financial support of the Regional Council of Provence- Alpes-Côte $\mathrm{d}^{\prime}$ Azur and with the financial support of the A*MIDEX ( $\mathrm{n}^{\circ}$ ANR-11-IDEX-0001-02), funded by the Investissements d'Avenir project funded by the French Government, managed by the French National Research Agency [ANR]). At time of submission an NSERC CGS-D supported BMR. EP was funded by the ANR ( ${ }^{\circ}$ ANR-18-CE02-0004-01). MAGR was supported by a Harrison McCain Visiting Professorship Award from the Harrison McCain Foundation.

\section{References}

Anderson S, Bankier AT, Barrell BG, de Bruijn MH, Coulson AR, Drouin J, Eperon IC, Nierlich DP, Roe BA, Sanger F, Schreier PH, Smith AJ, Staden R, Young IG (1981) Sequence and organization of the human mitochondrial genome. Nature 290:457-465

Allen JF (1996) Separate sexes and the mitochondrial theory of ageing. J Theor Biol 180:135-40 Altschul SF, Madden TL, Schäffer AA, Zhang J, Zhang Z, Miller W, Lipman DJ (1997) Gapped BLAST and PSI-BLAST: a new generation of protein database search programs. Nucl Acids Res 25:3389-3402 
Bayrer JR, Zhang W, Weiss MA (2005) Dimerization of doublesex is mediated by a cryptic ubiquitin-associated domain fold: implications for sex-specific gene regulation. J Biol Chem 280:32989-32996

Bettinazzi S, Plazzi F, Passamonti M (2016) The complete female-and male-transmitted mitochondrial genome of Meretrix lamarckii. PloS one 11.

Bettinazzi S, Rodríguez E, Milani L, Blier PU, Breton S (2019) Metabolic remodelling associated with mtDNA: insights into the adaptive value of doubly uniparental inheritance of mitochondria. Proc Roy Soc B 286:20182708

Bettinazzi S, Nadarajah S, Dalpé A, Milani L, Blier PU, Breton S (2020) Linking paternally inherited mtDNA variants and sperm performance. Phil Trans Roy Soc B 375:20190177

Biber E (2002) The Application of the Endangered Species Act to the Protection of Freshwater Mussels: A Case Study. Environ Law 32:91

Boore JL (1999) Animal mitochondrial genomes. Nucleic Acids Res 27:1767-1780

Boore JL, Medina M, Rosenberg LA (2004) Complete sequences of the highly rearranged molluscan mitochondrial genomes of the scaphopod Graptacme eborea and the bivalve Mytilus edulis. Mol Biol Evol 21:1492-1503

Breton S, Burger G, Stewart DT, Blier PU (2006) Comparative analysis of gender-associated complete mitochondrial genomes in marine mussels (Mytilus spp.). Genetics 172:11071119

Breton S, Beaupre HD, Stewart DT, Hoeh WR, Blier PU (2007) The unusual system of doubly uniparental inheritance of mtDNA: isn't one enough? Trends genet 23:465-74

Breton S, Beaupré HD, Stewart DT, Piontkivska H, Karmakar M, Bogan AE, Blier PU, Hoeh WR (2009a) Comparative mitochondrial genomics of freshwater mussels (Bivalvia: Unionoida) with doubly uniparental inheritance of mtDNA: gender-specific open reading frames and putative origins of replication. Genetics 183:1575-1589

Breton S, Stewart DT, Blier PU (2009b) Role-reversal of gender-associated mitochondrial DNA affects mitochondrial function in Mytilus edulis (Bivalvia: Mytilidae). J Exp Zool B 312:108-17

Breton S, Stewart DT, Hoeh WR (2010) Characterization of a mitochondrial ORF from the gender-associated mtDNAs of Mytilus spp. (Bivalvia: Mytilidae): identification of the "missing" ATPase 8 gene. Mar Genomics 3:11-18

Breton S, Stewart DT, Shepardson S, Trdan RJ, Bogan AE, Chapman EG, Ruminas AJ, Piontkivska H, Hoeh WR (2011a) Novel protein genes in animal mtDNA: a new sex determination system in freshwater mussels (Bivalvia: Unionoida)? Mol Biol Evol 28:1645-1659

Breton S, Ghiselli F, Passamonti M, Milani L, Stewart DT, Hoeh WR (2011b) Evidence for a fourteenth mtDNA-encoded protein in the female-transmitted mtDNA of marine mussels (Bivalvia: Mytilidae). PLoS One 6:e19365

Breton S, Milani L, Ghiselli F, Guerra D, Stewart DT, Passamonti M (2014) A resourceful genome: updating the functional repertoire and evolutionary role of animal mitochondrial DNAs. Trends Genet 30:555-64

Burt A, Trivers R (2006) Selfish mitochondrial DNA. Genes in Conflict: The Biology of Selfish Genetic Elements. Belknap Press of Harvard University, Cambridge, MA.

Burzyński A, Zbawicka M, Skibinski DOF,Wenne R (2003) Evidence for recombination of mtDNA in the marine mussel Mytilus trossulus from the Baltic. Mol Biol Evol 20: 388392 
Cao L, Kenchington E, Zouros E (2004a) Differential segregation patterns of sperm mitochondria in embryos of the blue mussel (Mytilus edulis). Genetics 166:883-894

Cao L, Kenchington E, Zouros E, Rodakis GC (2004b) Evidence that the large noncoding sequence is the main control region of maternally and paternally transmitted mitochondrial genomes of the marine mussel (Mytilus spp.). Genetics 167:835-850

Cao L, Ort BS, Mizi A, Pogson G, Kenchington E, Zouros E, Rodakis GC (2009) The control region of maternally and paternally inherited mitochondrial genomes of three species of the sea mussel genus Mytilus. Genetics 181:1045-1056

Capt C, Renaut S, Ghiselli F, Milani L, Johnson NA, Sietman BE, Stewart DT, Breton S (2018) Deciphering the link between doubly uniparental inheritance of mtDNA and sex determination in bivalves: clues from comparative transcriptomics. Genome Biol Evol 10:577-590

Capt C, Renaut S, Stewart DT, Johnson NA, Breton S (2019) Putative mitochondrial sex determination in the Bivalvia: insights from a hybrid transcriptome assembly in freshwater mussels. Frontiers Genet 10:840

Capt C, Bouvet K, Guerra D, Robicheau BM, Stewart DT, Pante E, Breton S (2020) Unorthodox features in two venerid bivalves with doubly uniparental inheritance of mitochondria. Sci Reports 10:1-3

Chakrabarti R, Walker JM, Stewart DT, Trdan RJ, Vijayaraghavana S, Curole JP, Hoeh WR (2006) Presence of a unique male-specific extension of C-terminus to the cytochrome $\mathrm{c}$ oxidase subunit II protein coded by the male-transmitted mitochondrial genome of Venustaconcha ellipsiformis (Bivalvia: Unionoidea). FEBS Lett 580:862-866

Chakrabarti R, Walker JM, Chapman EG, Shepardson SP, Trdan RJ, Curole JP, Watters GT, Stewart DT, Vijayaraghavana S, Hoeh WR (2007) Reproductive function for a Cterminus extended, male-transmitted cytochrome c oxidase subunit II protein expressed in both spermatozoa and eggs. FEBS Lett. 581:5213-5219

Chapman EG, Piontkivska H, Walker JM, Stewart DT, Curole JP, Hoeh WR (2008) Extreme primary and secondary protein structure variability in the chimeric male-transmitted cytochrome c oxidase subunit II protein in freshwater mussels: Evidence for an elevated amino acid substitution rate in the face of domain-specific purifying selection. BMC Evol Biol 8:165

Chase EE, Robicheau BM, Veinot S, Breton S, Stewart DT (2018) The complete mitochondrial genome of the hermaphroditic freshwater mussel Anodonta cygnea (Bivalvia: Unionidae): in silico analyses of sex-specific ORFs across order Unionoida. BMC Genomics 19:221

Clayton J, Douglas B, Morrison P (2018) West Virginia Mussel Survey Protocols. 24

Dickinson T (2018) Freshwater Mussel Surveys: I-26 Widening Final Report. NC Department of Transportation Raleigh, North Carolina 33

Cogswell AT, Kenchington ELR, Zouros E (2006) Segregation of sperm mitochondria in twoand four-cell embryos of the blue mussel Mytilus edulis : implications for the mechanism of doubly uniparental inheritance of mitochondrial DNA. Genome 49:799-807

Collin R (2013) Phylogenetic patterns and phenotypic plasticity of molluscan sexual systems. Integ Comp Biol 53: 723-735

Curole JP, Kocher TD (2002) Ancient sex-specific extension of the cytochrome c oxidase II gene in bivalves and the fidelity of doubly-uniparental inheritance. Mol Biol Evol19:1323-8 
Doucet-Beaupré H, Breton S, Chapman EG, Blier PU, Bogan AE, Stewart DT, Hoeh WR (2010) Mitochondrial phylogenomics of the Bivalvia (Mollusca): searching for the origin and mitogenomic correlates of doubly uniparental inheritance of mtDNA. BMC Evol Biol 10:50

Eads AR, Kennington WJ, Evans JP (2016) Interactive effects of ocean warming and acidification on sperm motility and fertilization in the mussel Mytilus galloprovincialis. Mar Ecol Prog Ser 562:101-11

Everett EM, Williams PJ, Gibson G, Stewart DT (2004) Mitochondrial DNA polymorphisms and sperm motility in Mytilus edulis (Bivalvia: Mytilidae). J Exp Zool A 301:906-10

Ferreira-Rodríguez N, Akiyama YB, Aksenova OV, Araujo R, Barnhart MC, Bespalaya YV, Bogan AE, Bolotov IN, Budha PB, Clavijo C, Clearwater SJ (2019) Research priorities for freshwater mussel conservation assessment. Biol Conser 231:77-87

Fisher C, Skibinski DOF (1990) Sex-biased mitochondrial DNA heteroplasmy in the marine mussel Mytilus. Proc Roy Soc Lond (B) 242:149-56

Fitzpatrick JL, Simmons LW, Evans JP (2012) Complex patterns of multivariate selection on the ejaculate of a broadcast spawning marine invertebrate. Evolution 66:2451-60

Garesse R, Vallejo CG (2001) Animal mitochondrial biogenesis and function: a regulatory crosstalk between two genomes. Gene 263:1-16

Gemmell NJ, Metcalf VJ, Allendorf FW (2004) Mother's curse: the effect of mtDNA on individual fitness and population viability. Trends Ecol Evol 19:238-44

Ghiselin MT (1969) The evolution of hermaphroditism among animals. Quart Rev Biol 44:189208.

Ghiselli F, Maurizii MG, Reunov A, Ariño-Bassols H, Cifaldi C, Pecci A, Alexandrova Y, Bettini S, Passamonti M, Franceschini V, Milani L (2019) Natural heteroplasmy and mitochondrial inheritance in bivalve molluscs. Integr Comp Biol 59:1016-1032

Ghiselli F, Milani L, Chang PL, et al (2012) De novo assembly of the manila clam Ruditapes philippinarum transcriptome provides new insights into expression bias, mitochondrial doubly uniparental inheritance and sex determination. Mol Biol Evol 29:771-786

Ghiselli F, Milani L, Guerra D, Chang PL, Breton S, Nuzhdin SV, Passamonti M (2013) Structure, transcription, and variability of metazoan mitochondrial genome: perspectives from an unusual mitochondrial inheritance system. Genome Biol Evol 5:1535-1554

Gissi C, Iannelli F, Pesole G (2008) Evolution of the mitochondrial genome of Metazoa as exemplified by comparison of congeneric species. Heredity 101:301-320

Guerra D, Ghiselli F, Passamonti M (2014) The largest unassigned regions of the male and female-transmitted mitochondrial DNAs in Musculista senhousia (Bivalvia, Mytilidae). Gene 536:316-325

Guerra D, Lopes-Lima M, Froufe E, Gan HM, Ondina P, Amaro R, Klunzinger MW, Callil C, Prié V, Bogan AE, Stewart DT (2019) Variability of mitochondrial ORFans hints at possible differences in the system of doubly uniparental inheritance of mitochondria among families of freshwater mussels (Bivalvia: Unionida). BMC Evol Biol 19

Guerra D, Plazzi F, Stewart DT, Bogan AE, Hoeh WR, Breton S (2017) Evolution of sexdependent mtDNA transmission in freshwater mussels (Bivalvia: Unionida). Sci Rep $7: 1551$

Gusman A, Lecomte S, Stewart DT, Passamonti M, Breton S (2016) Pursuing the quest for better understanding the taxonomic distribution of the system of doubly uniparental inheritance of mtDNA. PeerJ 4:e2760. 
Hansen D, Pilgrim D (1999) Sex and the single worm: sex determination in the nematode $C$. elegans. Mechanisms of Development 83:3-15

Hebert PDN, Gregory TR (2005) The promise of DNA barcoding for taxonomy. Syst Biol 54:852-859

Hebert PDN, Ratnasingham S, de Waard JR (2003) Barcoding animal life: cytochrome c oxidase subunit 1 divergences among closely related species. Proc Roy Soc B 270:S96-S99

Hodgkin J (1987) A genetic analysis of the sex-determining gene, tra-1, in the nematode Caenorhabditis elegans. Genes Dev 1:731-745

Hoeh WR, Blakley KH, Brown WM (1991) Heteroplasmy suggests limited biparental inheritance of Mytilus mitochondrial DNA. Science 251:1488-1490

Hoeh WR, Stewart DT, Saavedra C, Sutherland BW, Zouros E (1997) Phylogenetic evidence for role-reversals of gender-associated mitochondrial DNA in Mytilus (Bivalvia: Mytilidae). Mol Biol Evol 14:959-967

Hoeh WR, Stewart DT, Guttman SI (2002) High fidelity of mitochondrial genome transmission under the doubly uniparental mode of inheritance in freshwater mussels (Bivalvia: Unionoidea). Evolution 56:2252-2261

Hoffmann RJ, Boore JL, Brown WM (1992) A novel mitochondrial genome organization for the blue mussel, Mytilus edulis. Genetics 131:397-412

Huber M (2010) Compendium of bivalves. ConchBooks, Germany.

Hurst LD, Hoekstra RF (1994). Shellfish gees kept in line. Nature 368:817-818

Inoue K, Hayes DM, Harris JL, Christian AD (2013) Phylogenetic and morphometric analyses reveal ecophenotypic plasticity in freshwater mussels Obovaria jacksoniana and Villosa arkansasensis (Bivalvia: Unionidae). Ecol Evol 3:2670-2683

Jeratthitikul E, Phuangphong S, Sutcharit C, et al (2019) Integrative taxonomy reveals phenotypic plasticity in the freshwater mussel Contradens contradens (Bivalvia: Unionidae) in Thailand, with a description of a new species. Syst Biodiv 17:134-147

Jha M, Côté J, Hoeh WR, Blier PU, Stewart DT (2008) Sperm motility in Mytilus edulis in relation to mitochondrial DNA polymorphisms: implications for the evolution of doubly uniparental inheritance in bivalves. Evolution 62:99-106

Johnson NA, Smith CH, Pfeiffer JM, Randklev CR, Williams JD, Austin JD. (2018) Integrative taxonomy resolves taxonomic uncertainty for freshwater mussels being considered for protection under the U.S. Endangered Species Act. Sci Reports 8:1-16

Kenchington E, MacDonald B, Cao L, et al (2002) Genetics of mother-dependent sex ratio in blue mussels (Mytilus spp.) and implications for doubly uniparental inheritance of mitochondrial DNA. Genetics 161:1579-88

Kenchington EL, Hamilton L, Cogswell A, Zouros E (2009) Paternal mtDNA and maleness are co-inherited but not causally linked in mytilid mussels. PLoS One 4

Kulkarni M, Smith HE (2008) E1 Ubiquitin-activating enzyme UBA-1 plays multiple roles throughout $C$. elegans development. PLoS Genet 4:e1000131

Kyriakou E, Kravariti L, Vasilopoulos T, Zouros E, Rodakis GC (2015) A protein binding site in the M mitochondrial genome of Mytilus galloprovincialis may be responsible for its paternal transmission. Gene 562:83-94

Kyriakou E, Kravariti L, Zouros E, Rodakis GC (2016) No sex-specific protein-binding site in the VD1 of the F mitochondrial genome of the mussel Mytilus galloprovincialis. Gene Reports 5:148-150 
Ladoukakis ED, Zouros E (2001) Direct evidence for homologous recombination in mussel (Mytilus galloprovincialis) mitochondrial DNA. Mol Biol Evol 18:1168-75

Levitan Don R. 2000 Sperm velocity and longevity trade off each other and influence fertilization in the sea urchin Lytechinus variegatus. Proc Roy Sc Lond B 267:531-4

Leonard JL (2019) Transitions between sexual systems: understanding the mechanisms of, and pathways between, dioecy, hermaphroditism and other sexual systems. Springer

Lee Y, Kwak H, Shin J, Kim SC, Kim T, Park JK (2019) A mitochondrial genome phylogeny of Mytilidae (Bivalvia: Mytilida). Mol Phylogenet Evol 139:106533

Liu G, Innes D, Thompson RJ (2011) Quantitative analysis of sperm plane circular movement in the blue mussels Mytilus edulis, M. trossulus and their hybrids. J Exp Zool A 315A:28090

Lopes-Lima M, Burlakova LE, Karatayev AY, Mehler K, Seddon M, Sousa R (2018) Conservation of freshwater bivalves at the global scale: diversity, threats and research needs. Hydrobiologia 810:1-14

Lopes-Lima M, Froufe E, Ghamizi M, Mock KE, Kebapçı Ü, Klishko O, Kovitvadhi S, Kovitvadhi U, Paulo OS, Pfeiffer III JM, Raley M (2017) Phylogeny of the most speciesrich freshwater bivalve family (Bivalvia: Unionida: Unionidae): Defining modern subfamilies and tribes. Mol Phylogen Evol 106:174-191

Lubośny M, Przyłucka A, Śmietanka B, Breton S, Burzyński A (2018) Actively transcribed and expressed atp8 gene in Mytilus edulis mussels. PeerJ 6:e4897

Lubośny M, Śmietanka B, Przyłucka A, Burzyński A (2020) Highly divergent mitogenomes of Geukensia demissa (Bivalvia, Mytilidae) with extreme AT content. J Zool Syst Evol Res doi.org/10.1111/jzs.12354

Lymbery RA, Kennington WJ, Evans JP (2017) Egg chemoattractants moderate intraspecific sperm competition. Evol Lett 1:317-27

McCartney MA, Auch B, Kono T, Mallez S, Zhang Y, Obille A, Becker A, Abrahante JE, Garbe J, Badalamenti JP, Herman A (2019) The Genome of the Zebra Mussel, Dreissena polymorpha: A Resource for Invasive Species Research. BioRxiv 1:696732.

McGinnis S, Madden TL (2004) BLAST: at the core of a powerful and diverse set of sequence analysis tools. Nucl Acids Res 32:W20-W25

Milani L (2015) Mitochondrial membrane potential: a trait involved in organelle inheritance? Biol Lett 11(10)

Milani L, Ghiselli F (2015) Mitochondrial activity in gametes and transmission of viable mtDNA. Biol Direct 10:22

Milani L, Ghiselli F, Guerra D, Breton S, Passamonti M (2013) A comparative analysis of mitochondrial ORFans: new clues on their origin and role in species with doubly uniparental inheritance of mitochondria. Genome Biol Evol. 5:1408-1434

Milani L, Ghiselli F, Maurizii MG, Passamonti M (2011) Doubly uniparental inheritance of mitochondria as a model system for studying germ line formation. PLoS One 6

Milani L, Ghiselli F, Maurizii MG, Nuzhdin SV, Passamonti M (2014) Paternally transmitted mitochondria express a new gene of potential viral origin. Gen Biol Evol 6:391-405

Mitchell A, Guerra D, Stewart D, Breton S (2016) In silico analyses of mitochondrial ORFans in freshwater mussels (Bivalvia: Unionoida) provide a framework for future studies of their origin and function. BMC Genomics 17:597

Mizi A, Zouros E, Moschonas N, Rodakis GC (2005) The complete maternal and paternal mitochondrial genomes of the Mediterranean mussel Mytilus galloprovincialis: 
implications for the doubly uniparental inheritance mode of mtDNA. Mol Biol Evol 22:952-967

Muratani M, Kung C, Shokat KM, Tansey WP (2005) The F box protein Dsg1/Mdm30 is a transcriptional coactivator that stimulates Gal4 turnover and cotranscriptional mRNA processing. Cell 120:887-899

Nishiwaki K, Kubota Y, Chigira Y, Roy SK, Suzuki M, Schvarzstein M, Jigami Y, Hisamoto N, Matsumoto K (2004) An NDPase links ADAM protease glycosylation with organ morphogenesis in C. elegans. Nat Cell Biol 6:31-37

Obata M, Komaru A (2005) Specific location of sperm mitochondria in mussel Mytilus galloprovincialis zygotes stained by MitoTracker. Develop Growth Diff 47:255-263

Oliver M, Evans JP (2014) Chemically moderated gamete preferences predict offspring fitness in a broadcast spawning invertebrate. Proc Biol Sci 281:20140148

Ouimet P, Kienzle L, Lubosny M, Burzyński A, Angers A, Breton S (2020) The ORF in the control region of the female-transmitted Mytilus mtDNA codes for a protein. Gene 725:144161

Pante E, Poitrimol C, Saunier A, Becquet V, Garcia P (2017) Putative sex-linked heteroplasmy in the tellinid bivalve Limecola balthica (Linnaeus, 1758). J Moll Stud 83:226-228

Park H, Ahn DH (2015) Complete mitochondrial genome of the Antarctic soft-shelled clam, Laternula elliptica (Bivalvia; Laternulidae). Mitochond DNA 26:642-3

Passamonti M, Ghiselli F (2009) Doubly uniparental inheritance: two mitochondrial genomes, one precious model for organelle DNA inheritance and evolution. DNA Cell Biol 28:7989

Passamonti M, Ricci A, Milani L, Ghiselli F (2011) Mitochondrial genomes and doubly uniparental inheritance: new insights from Musculista senhousia sex-linked mitochondrial DNAs (Bivalvia Mytilidae). BMC Genomics 12:442

Passamonti M, Plazzi F (2020) Doubly Uniparental Inheritance and beyond: The contribution of the Manila clam Ruditapes philippinarum. J. Zool Syst Evol Res doi.org/10.1111/jzs. 12371

Plazzi F, Passamonti M (2019) Footprints of unconventional mitochondrial inheritance in bivalve phylogeny: signatures of positive selection on clades with doubly uniparental inheritance.

J Zool Syst Evol Res 57:258-271

Plazzi F, Puccio G, Passamonti M (2016) Comparative large-scale mitogenomics evidences clade-specific evolutionary trends in mitochondrial DNAs of bivalvia. Genome Biol Evol 8:2544-2564

Plazzi F, Ribani A, Passamonti M (2013) The complete mitochondrial genome of Solemya velum (Mollusca: Bivalvia) and its relationships with Conchifera. BMC Genomics 14:409

Pozzi A, Plazzi F, Milani L, Ghiselli F, Passamonti M (2017) SmithRNAs: could mitochondria "bend" nuclear regulation? Mol Biol Evol 34:1960-73

Régnier C, Fontaine B, Bouchet P (2009) Not knowing, not recording, not listing: numerous unnoticed mollusk extinctions. Cons Biol 23:1214-1221

Reis J, Machordom A, Araujo R (2013) Morphological and molecular diversity of Unionidae (Mollusca, Bivalvia) from Portugal. https://doi.org/10.3989/graellsia.2013.v69.075

Riccardi N, Froufe E, Bogan AE, Zieritz A, Teixeira A, Vanetti I, Varandas S, Zaccara S, Nagel KO, Lopes-Lima M (2019) Phylogeny of European Anodontini (Bivalvia: Unionidae) with a re-description of Anodonta exulcerata. Zool J Linn Soc. doi.org/10.1093/zoolinnean/zlz136 
Robicheau BM, Breton S, Stewart DT (2017a) Sequence motifs associated with paternal transmission of mitochondrial DNA in the horse mussel, Modiolus modiolus (Bivalvia: Mytilidae). Gene 605:32-42

Robicheau BM, Powell AE, Del Bel L, Breton S, Stewart DT (2017b ). Evidence for extreme sequence divergence between the male- and female-transmitted mitochondrial genomes in the bivalve mollusc, Modiolus modiolus (Mytilidae). J Zool Syst Evol Res 55:89-97

Robicheau BM, Chase EE, Hoeh WR, Harris JL, Stewart DT, Breton S (2018) Evaluating the utility of the female-specific mitochondrial $f$-orf gene for population genetic, phylogeographic and systematic studies in freshwater mussels (Bivalvia: Unionida). PeerJ 6:e5007

Saavedra C, Reyero M-I, Zouros E (1997) Male-dependent doubly uniparental inheritance of mitochondrial dna and female-dependent sex-ratio in the mussel Mytilus galloprovincialis. Genetics 145:1073-1082

Salghetti SE (2001) Regulation of transcriptional activation domain function by ubiquitin. Science 293:1651-1653

Sato M, Sato K (2013) Maternal inheritance of mitochondrial DNA by diverse mechanisms to eliminate paternal mitochondrial DNA. Biochim Biophys Acta - Mol Cell Res 1833:1979-84

Shea CP, Peterson JT, Wisniewski JM, Johnson NA (2011) Misidentification of freshwater mussel species (Bivalvia:Unionidae): contributing factors, management implications, and potential solutions. J North Amer Benth Soc 30:446-458

Shi J, Hong Y, Sheng J, Peng K, Wang J. (2015) De novo transcriptome sequencing to identify the sex-determination genes in Hyriopsis schlegelii. Biosci Biotech Biochem 79:12571265

Śmietanka B, Burzyński A, Wenne R (2010) Comparative genomics of marine mussels (Mytilus spp.) gender associated mtDNA: rapidly evolving atp8. J Mol Evol 71:385-400

Śmietanka, B, Lubośny M, Przyłucka A, Gérard K, Burzyński A (2018) Mitogenomics of Perumytilus purpuratus (Bivalvia: Mytilidae) and its implications for doubly uniparental inheritance of mitochondria. PeerJ 6:e5593

Smith DR (2006) Survey design for detecting rare freshwater mussels. J North Amer Benth Soc 25:701-711

Soroka M, Burzyński A (2017) Hermaphroditic freshwater mussel Anodonta cygnea does not have supranumerary open reading frames in the mitogenome. Mitochondrial DNA Part B 2:862-864

Stewart DT, Breton S, Blier PU, Hoeh WR (2009) Masculinization events and doubly uniparental inheritance of mitochondrial DNA: a model for understanding the evolutionary dynamics of gender-associated mtDNA in mussels. In Evolutionary Biology 163-173. Springer, Berlin, Heidelberg

Stewart DT, Jha M, Breton S, Hoeh WR, Blier PU (2012) No effect of sperm interactions or egg homogenate on sperm velocity in the blue mussel, Mytilus edulis (Bivalvia: Mytilidae). Can J Zool 90:1291-6

Vallès Y, Boore JL. 2006. Lophotrochozoan mitochondrial genomes. Integr Comp Biol 46:544557

Zbawicka M, Skibinski D, Wenne R (2003) Doubly uniparental transmission of mitochondrial DNA length variants in the mussel Mytilus trossulus. Mar Biol 142: 455-460 
Zieritz A, Geist J, Gum B (2014) Spatio-temporal distribution patterns of three stream-dwelling freshwater mussel species: towards a strategy for representative surveys. Hydrobiologia 735:123-136

Zieritz A, Hoffman JI, Amos W, Aldridge DC (2010) Phenotypic plasticity and genetic isolationby-distance in the freshwater mussel Unio pictorum (Mollusca: Unionoida). Evol Ecol 24:923-938

Zouros E, Freeman KR, Ball AO, Pogson GH (1992) Direct evidence for extensive paternal mitochondrial DNA inheritance in the marine mussel Mytilus. Nature 359:412-4

Zouros E (2013) Biparental inheritance through uniparental transmission: the doubly uniparental inheritance (DUI) of mitochondrial DNA. Evol Biol 40:1-31

Zouros E, Rodakis GC (2019) Doubly uniparental inheritance of mtDNA: An unappreciated defiance of a general rule. In Cellular and Molecular Basis of Mitochondrial Inheritance, 25-49 Springer, Cham.

Zouros E (2020) Doubly uniparental inheritance of mitochondrial DNA: Might it be simpler than we thought? J Zool Syst Evol Res doi.org/10.1111/jzs.12364 